\title{
Cartas prodigiosas. Juan E. O'Leary y los entresijos de la edición de sus relatos históricos sobre la Guerra del Paraguay (1919-1929)
}

\author{
Prodigious letters. Juan E. O'Leary and the in and out of the \\ edition of his historical accounts about the War of Paraguay \\ (1919-1929)
}

\author{
Liliana M. Brezzo \\ Consejo Nacional de Investigaciones Científicas y Técnicas, \\ Instituto de Estudios Históricos, Económicos, Sociales e Internacionales, \\ Nodo Instituto de Historia y Pontificia Universidad Católica Argentina (Argentina) \\ lilianabrezzo@gmail.com \\ lilianabrezzo@conicet.gov.ar
}

\section{Resumen}

Uno de los conjuntos paraguayos de correspondencia más abundantes de la primera mitad del siglo veinte es el del historiador Juan Emiliano O'Leary Urdapilleta (1879 -1969). Este acervo inédito permite trazar una cartografía de las relaciones epistolares familiares, de amistad e intelectuales. Dentro de la correspondencia intelectual figura la que se vincula con la gestación y edición de los relatos históricos de O’Leary sobre la Guerra del Paraguay. Este trabajo resume los resultados de un análisis que entrecruza esas piezas epistolares con la producción histórica sobre ese conflicto que publicó entre 1919 y 1929. Con este estudio se pretende reconstruir la genealogía intelectual de O'Leary y acrecentar el conocimiento sobre los mecanismos de configuración de un movimiento historiográfico revisionista sobre la Guerra del Paraguay que trascendió el espacio del Río de la Plata, y en particular del denominado revisionismo paraguayo.

\section{Palabras clave}

Guerra del Paraguay; Historiadores; Correspondencia intelectual; Historiografía; Revisionismo histórico.

\footnotetext{
Abstract

One of the most abundant Paraguayan correspondence sets of the first half of the twentieth century is that of the historian Juan Emiliano O'Leary Urdapilleta (1879 -1969). This unpublished collection allows us to draw a cartography of family, friendship and intellectual epistolary relationships. Within the intellectual correspondence figure linked to the

Esta obra está sujeta a la Licencia Reconocimiento-NoComercial-CompartirIgual 4.0 Internacional de Creative Commons. http://creativecommons.org/licenses/by-nc-sa/4.0/ 


\section{Liliana M. Brezzo}

gestation and edition of the historical production of O'Leary on the War of Paraguay. This work summarizes the results of an analysis that interweaves the epistolary pieces with the historical stories about the war published between 1919 and 1929. It is intended to reconstruct the intellectual genealogy of O'Leary and increase knowledge about the mechanisms of configuration of a revisionist historiographic movement on the War of Paraguay that transcended the space of the Río de la Plata, and in particular of the so-called Paraguayan revisionism.

\section{Keywords}

War of Paraguay; Historians; Intellectual correspondence; Historiography; Historical revisionism.

Uno de los conjuntos paraguayos de correspondencia más abundantes de la primera mitad del siglo veinte es el del historiador Juan Emiliano O'Leary Urdapilleta (18791969). La conversación mantenida a distancia, desde Asunción y desde los sucesivos destinos diplomáticos, con amigos, colegas y rivales políticos, dio origen a un voluminoso acervo epistolar, comprendido entre los años 1899 y 1969, importante no únicamente por la cartografía de las relaciones familiares, de amistad e intelectuales que permite reconstruir, sino también por el propio contenido de las cartas, en las que los interlocutores se extienden sobre sus emociones, sus posturas políticas, las interpretaciones del pasado, las proyectos personales y profesionales. Al igual que en otros casos de letrados en América Latina, es posible distinguir distintos significados y funciones en la correspondencia intelectual de 0'Leary: el debate, es decir, la confrontación de puntos de vista opuestos o no necesariamente coincidentes, provocada muchas veces por uno de los dos corresponsales; la definición del propio pensamiento o el uso del medio de la escritura con un destinatario específico para "pasar en limpio" una reflexión quizás no del todo clara en un primer momento; la justificación a posteriori de posiciones tomadas que habían alcanzado estado público y la proyección hacia la posteridad de la propia figura como intelectual, donde las cartas resultan no solo ser el vehículo vivo de un pensamiento en movimiento sino el registro permanente del mismo. (Myers, 20142015; Myers, 2010; Pita y Marichal, 2019)

El robusto acervo de cartas se explica, en parte, por la extensa trayectoria político cultural de O'Leary, de sus actividades como periodista (a partir de su incorporación, en 1900, como columnista del diario La Patria), como diplomático (fue Encargado de Negocios en España, 1925-1929; Ministro Plenipotenciario en España, 1936; Ministro Plenipotenciario en Italia, 1936-1937 y 1947-1948 y Embajador ante la Santa Sede, 1951-1954) y, fundamentalmente, como historiador, a partir de las publicaciones en la prensa, desde el año 1902, de la serie conocida como Recuerdos de Gloria, y de la extendida polémica sobre la interpretación de la historia del Paraguay que sostuviera con Cecilio Báez.

O'Leary integró el grupo de intelectuales paraguayos que se conoce como la Generación del 900. Nacidos en su mayoría en la primera década de la posguerra del Paraguay, entre 1870 y 1880, sus integrantes comenzaron a vehiculizar sus afanes culturales a través de distintos canales en entre siglos diecinueve y veinte; el 


\section{Cartas prodigiosas. Juan E. O'Leary y los entresijos de la edición de sus relatos históricos sobre la Guerra del Paraguay (1919-1929)}

principal fue la prensa, pero también participaron en la gestación y edición de revistas que tuvieron cierta acogida en el espacio cultural asunceno, como la Revista del Instituto Paraguayo, la Revista de la Universidad Nacional, la Revista de Agronomía y de Ciencias Aplicadas. La correspondencia de O’Leary da cuenta de esas aspiraciones colectivas. Con excepción de los intercambios que mantuviera con el diplomático paraguayo Gregorio Benites, entre los años 1900-1909, los más antiguos parecen haber sido aquellos con miembros de esa generación: a partir de 1904 se conservan cartas intercambiadas con Arsenio López Decoud (1904-1927), Fulgencio Moreno (1912-1933), Enrique Solano López (1910-1914); desde 1920 con Manuel Domínguez (1924-1928), con Justo Pastor Benítez (1924-1935), y con letrados cercanos a esa promoción intelectual, como el caso de Juan Natalicio González, a quien 0'Leary consideró como su dilecto discípulo y con quien mantuvo una correspondencia que, con escasas interrupciones, fue constante entre los años 1920 y 1963.

Desde los primeros años del siglo XX O’Leary buscó el trato epistolar con intelectuales extranjeros como el uruguayo Luis Alberto de Herrera (1905-1954), cuyos intercambios cubren más de cincuenta años de acuerdos y desacuerdos políticos e historiográficos; también, desde 1915, con el venezolano Rufino Blanco Fombona (hasta 1939); desde 1926 con el mexicano Carlos Pereyra (1926-1940), con los argentinos Ernesto Quesada (1920-1926) y David Peña (1907-1928) y con el uruguayo José Enrique Rodó (1915), intercambio este último que parece haber abarcado algo más del límite cronológico que impone la prueba documental.

Con inmigrantes europeos que, al decir de Milda Rivarola, contribuyeron también a "crear el novecentismo paraguayo" (Rivarola, 2007) fue con el economista ruso Rodolfo Ritter con quien O'Leary mantuvo una amplia correspondencia (se conservan más de doscientas cartas intercambiadas entre 1916 y 1946) rebosante de intimidad y de porfía sobre la vida política y cultural paraguaya; con el naturalista suizo Moisés Bertoni (1918-1928) a través de cuyas misivas pueden reconstruirse los inicios de los estudios de agronomía en el Paraguay ${ }^{1}$, con el escritor español Viriato Díaz Pérez que fue, desde su llegada al país en 1906 y, por algún tiempo, uno de sus más cercanos amigos. Entre los diplomáticos, sobresale la conversación epistolar con el Cónsul General de Paraguay en Madrid, Fernando Pignet, incansable corresponsal entre los años 1925 y 1950, con el diplomático peruano Alberto Rey de Castro (1922-1949), con Ramón Caballero, Encargado de Negocios del Paraguay en Francia (1925-1961) y, esporádicamente, con el embajador de España en el Paraguay, Ernesto Giménez Caballero (1958).

En esa constelación de relaciones epistolares figuran las que se refieren a la gestación y edición de sus relatos históricos sobre la Guerra del Paraguay. En este

\footnotetext{
${ }^{1}$ Además de las piezas epistolares inéditas de Moisés Bertoni conservadas en la Colección de Juan E. O'Leary, se han dado a conocer otros rastros de la correspondencia entre O'Leary y Bertoni, como en la biografía producida por Danilo Baratti y Patrizia Candolfi. Vida y obra del sabio Bertoni. Asunción, Servilibro, 2019, pp. 286-293.
} 


\section{Liliana M. Brezzo}

estudio pretendemos examinar las cartas, inéditas, vinculadas a tres obras: Nuestra Epopeya. Guerra del Paraguay (1919), El Mariscal Solano López (1920 y 1925) y El Centauro de Ybicuy. Vida heroica del general Bernardino Caballero (1929). El examen tiene el propósito de contribuir a reconstruir la genealogía intelectual de 0’Leary y su discurso histórico conocido, en el argot historiográfico, como revisionismo paraguayo, así como acrecentar el conocimiento sobre los mecanismos de configuración de un movimiento historiográfico revisionista sobre la Guerra del Paraguay que trascendió el espacio del Río de la Plata. Interesa subrayar la operación política que hace 0'Leary con el uso de esas cartas, las que las transforma en prodigiosas, increíbles, asombrosas.

Si bien O'Leary fue una de las figuras públicas más relevantes de la primera mitad del siglo XX en el Paraguay, su correspondencia parece develar que fue su oficio de historiador el que rigió todas sus demás actividades, es decir, que su actividad vital parece haber sido indisociable de su función como historiador. Por ello, la perspectiva que adopta este trabajo se inscribe dentro de una serie de enfoques recientes situados en el campo de la historia de la historiografía, cuyos autores concuerdan en subrayar la importancia de lo personal insertado en el discurso académico e intelectual, conexa a un mundo científico en el que aumenta incesantemente la necesidad de la auto conciencia, la representatividad de lo singular y la reflexión epistemológica, las que requieren nuevas formas de expresión para la comprensión de los procesos de escritura de la historia. Jeremy Popkin (2005), Ignacio Peiró Martín (2001) y Jaume Aurell (2008), entre otros estudiosos, se han interesado en mostrar que el itinerario personal de los historiadores y sus relaciones familiares, de amistad, intelectuales, no son un hecho accidental en su carrera profesional, sino que, de un modo bastante complejo, condiciona el entero proceso de la investigación, de la elección de los temas y de sus enfoques.

El andamiaje metodológico de la investigación que resume este artículo ha supuesto, asimismo, el entrecruzamiento con herramientas provenientes de la crítica literaria, atendiendo a distintas expresiones del denominado "espacio biográfico", que comprende biografías, autobiografías, memorias, testimonios, diarios íntimos, correspondencias, cuadernos de viajes, borradores, entre otros formatos; una perspectiva que resalta la utilidad de las distintas formas de auto-escritura como fuentes para comprender mejor la manera en que los historiadores construyen el acceso al conocimiento del pasado, o sea, sus propios textos históricos. (Aurell, 2014; Peluffo y Maíz, 2018; Costa Motta y de Souza Fredrigo, 2018). De este modo, el estudio de la correspondencia de Juan E. O'Leary puede producir conocimiento en una doble dirección. Por un lado, en cuanto al análisis del historiador y su evidente dimensión social, es decir, comprenderlo mejor en $s u$ historia y la historia que él ha narrado y, en otro sentido, percibir mejor hasta qué punto ha sido moldeado por el contexto en el que transcurrió su actuación profesional y la aparición de su producción histórica (Halperin Donghi, 2008; Saitta, 2018).

\section{Nuestra Epopeya}


Dentro del ciclo conmemorativo del cincuentenario de la Guerra del Paraguay (1914-1920), 0'Leary dio a conocer dos obras: Nuestra Epopeya. Guerra del Paraguay, publicada en 1919, y la primera edición de El Mariscal López, en 1920. Se trata de dos textos de envergadura si se tiene en cuenta la acotada producción histórica que había dado a conocer desde el año 1902. Cómo ha sido apuntado más arriba, en el diario La Patria, de Asunción, había publicado sus primeros escritos históricos bajo el título general de Recuerdos de Gloria. Los artículos tenían como propósito, según sus propias palabras, "exaltar el heroísmo del pueblo vencido en una lucha desigual" y "exponer a las nuevas generaciones las hazañas de los héroes de la Guerra del Paraguay contra la Triple Alianza” (O’Leary , 2007). Protagonizó también, en la prensa asuncena, una polémica trascendente con el abogado Cecilio Báez. Fue la primera disputa historiográfica que se produjo en el país referida a determinar, además de otras cuestiones, los orígenes y las responsabilidades en la Guerra del Paraguay contra la Triple Alianza. ${ }^{2}$ Mientras que Báez los explicó como un efecto del propio "sistema tiránico" paraguayo de la primera mitad del siglo XIX, que abarcó los gobiernos de José Gaspar de Francia (1814-1840), de Carlos A. López (1844-1862) y de Francisco S. López (1862-1870), 0’Leary pergeñó un discurso histórico centrado en un pasado heroico y glorioso, en el que la sociedad paraguaya vivía feliz y próspera hasta que una serie de causas exógenas -los imperialismos brasileño y argentino- la habían condenado a su completa postración. La victoria retórica frente a Báez supuso, para O’Leary, un fuerte espaldarazo público que se proyectó más allá de los límites de la ciudad de Asunción y, sobre todo, los apoyos que recibiera durante los debates dieron cuenta de cierta demanda, por parte de la sociedad, de su interpretación del pasado (Capdevila, 2008).

Su creciente prestigio en el espacio cultural y dentro de las filas de la Asociación Nacional Republicana o Partido Colorado lo prefiguraban, en la primera década del siglo XX, como una figura pública relevante. En ese contexto debe inscribirse la correspondencia que mantuvo con el diplomático paraguayo Gregorio Benites entre los años 1900-1909, es decir, hasta el fallecimiento de este último, que devela los tempranos y mancomunados esfuerzos para construir en el Paraguay, mediante publicaciones y actos conmemorativos, una lectura de la guerra. El intercambio epistolar da cuenta, por ejemplo, de los mecanismos de exaltación desplegados por ambos para ubicar al jurisconsulto argentino Juan Bautista Alberdi como "prócer paraguayo" fundándose en la posición intelectual que detentara durante la guerra. Benites, otrora funcionario de la legación paraguaya en Europa durante el conflicto bélico, amigo personal de Alberdi, y con quien mantuvo una intensa correspondencia por más de dos décadas, halló en el joven historiador su principal aliado en el propósito de exaltación del tucumano. Por parte de O’Leary, la

\footnotetext{
2 Polémica sobre la Historia del Paraguay. Compilación y edición de los textos a cargo de Ricardo Scavone Yegros y Sebastián Scavone Yegros. Estudio preliminar de Liliana M. Brezzo. Asunción, Tiempo de Historia, (2008) 2012, pp. 11-65.
} 


\section{Liliana M. Brezzo}

correspondencia pone de manifiesto la apropiación de la figura de Alberdi, presentándolo no únicamente como defensor intelectual de la causa paraguaya durante el conflicto, sino como "admirador" de Francisco Solano López y de su política en el Río de la Plata (Brezzo, 2012).

Precedido de estos antecedentes en 1919 publicó en Asunción, con el sello editorial La Mundial, el libro Nuestra Epopeya. Guerra del Paraguay, dentro de la colección "Biblioteca Paraguaya del Centro de Estudiantes de Derecho" de la Universidad Nacional de Asunción (Caballero Campos, 2017). La obra, con una extensión de 651 páginas, consistía en una compilación de textos ya divulgados por O'Leary en distintos formatos -artículos periodísticos, folletos, conferencias- que configuraban, según los editores, una "literatura patria”, cuyo propósito era levantar el espíritu y fortalecer el patriotismo a la espera de poder dar a conocer su "obra definitiva y monumental sobre la tragedia americana que sufriera el Paraguay"

En la portada del libro, como subtítulo, figuraba la leyenda "Juicio de José Enrique Rodó". En concreto, se trata de una carta que el filósofo le escribiera a O'Leary en 1915, y que este último utilizaba como prólogo. El fugaz intercambio epistolar entre O’Leary y Rodó - sólo se conserva el original de la pieza epistolar en cuestión- se había iniciado a instancias del historiador uruguayo Luis Alberto Herrera, con quien el escritor paraguayo cultivaba relaciones epistolares desde 1902. La conversación a distancia evolucionaría en una sólida amistad que se prolongaría hasta el fallecimiento de Herrera, en 1959, fogueada, en parte, por la operación historiográfica en que se empeñarían ambos corresponsales para impulsar y consolidar, en el ámbito platense, una lectura revisionista de la Guerra de la Triple Alianza (Reali, 2012). Dentro de esto último, la comunicación entre Herrera y O'Leary da cuenta de una estrategia bien definida que apunta a "sumar" a la causa común a otros autores. Así, por ejemplo, en 1915, diversas cartas de O’Leary nos informan sobre sus intercambios con intelectuales uruguayos a quienes intenta "convertir" a su causa, entre los que se halla José Enrique Rodó. En una carta fechada el 24 de julio de 1915, el autor paraguayo señalaba a ese respecto a Herrera: "Don Luis Melián Lafinur, cada vez más amable, me ha escrito una segunda cariñosa carta. El que se me ha callado es Rodó. Más ya lo [desataré] con cartas, envíos y amabilidades. Tengo que convertirlo. Por cada correo le va algo mío. Y no desespero de conseguir amansarlo. Una palabra suya, una opinión favorable sería una gran cosa ¿no es verdad amigazo?”3 Algunos días más tarde, en una carta del 7 de agosto, retoma la cuestión comunicándole a Herrera que:

El gran Rodó habló, o, mejor dicho, escribió, por fin. Acabo de recibir una notable carta suya, en la que juzga mi trabajo del álbum gráfico, y me da su opinión sobre la guerra. El juicio muy amable, la opinión muy ecuánime dentro del coloradismo de Rodó. El hombre ya no es la fiera aquella que

\footnotetext{
${ }^{3}$ Carta de Juan E. O’Leary a Luis A. de Herrera, Asunción, 24 de Julio de 1915. Reproducida en Liliana M. Brezzo y María Laura Reali. Combatir con la pluma en la mano. Dos intelectuales en la Guerra del Chaco: Juan E. O'Leary y Luis Alberto de Herrera. Asunción, Servilibro, 2017, p.38.
} 


\section{Cartas prodigiosas. Juan E. O'Leary y los entresijos de la edición de sus relatos históricos sobre la Guerra del Paraguay (1919-1929)}

dirigió a un colega suyo la carta de felicitación que Ud. recordará cuando el famoso debate sobre aumento de pensión a los veteranos de la defensa y del Paraguay. 4

O'Leary enumeraba, a continuación, las principales "conclusiones" a las que, según entendía, había arribado el filósofo uruguayo: reconocía la responsabilidad de la Triple Alianza en "el exterminio del pueblo vencido", destacaba la defensa heroica de los paraguayos y evocaba el gesto de la "espontánea devolución de los trofeos" nacida "del seno del Partido político que llevó al Uruguay a la guerra". Y agregaba: "Creo que no se puede pedir más. Voy a hacer copiar a máquina la carta íntegra para mandársela. Puede que la publique, por más que los elogios que me prodiga podían hacer creer que hay un poco de vanidad de mi parte". 5

Un examen del texto completo de la carta de Rodó nos permite restituir algunos de los términos desglosados por O’Leary a Herrera. Para comenzar, el filósofo uruguayo escribió:

He considerado siempre que la guerra entre la Triple Alianza y el Paraguay es uno de los hechos más complejos de la historia sudamericana y en algunas de sus relaciones, uno de los que imponen al crítico desapasionado y leal mayores torturas de conciencia para completar un juicio cabal y seguro que, sin olvido de ninguno de sus antecedentes y circunstancias con que se vincula aquella inmensa tragedia, en la vida interna e internacional, de los cuatro pueblos que fueron sus actores, permita distribuir con justicia las tremendas responsabilidades que ella envuelve y fijar, a su respecto, el veredicto histórico. (República del Paraguay, Biblioteca Nacional del Paraguay, Colección Juan E. O’Leary, Correspondencia privada y oficial (en adelante BNP - CJO). Carpeta XXXIV. Carta de José Enrique Rodó a Juan E. O’Leary, Montevideo, 27 de julio de 1915)

En cuanto a la responsabilidad de los vencedores Rodó escribía que "la devastación y el exterminio del pueblo vencido en esa guerra son un horror que, aunque no entró, sin duda, en el plan deliberado de los vencedores, determina para ellos grave responsabilidad, y se sobrepone, como efecto moral de la victoria, al propósito de liberación sincera en algunos -no ciertamente en todas- de las voluntades que prepararon la Alianza, o la aceptaron, o la dirigieron en la guerra". ${ }^{6}$

El texto de la carta-prólogo impresa en 1919 y el manuscrito original enviado por Rodó a O'Leary, en 1915, son idénticos. De modo que O'Leary no seleccionó algunos fragmentos de la misiva para insertarla en Nuestra Epopeya, así como lo hiciera al comentar su contenido en la carta a Herrera referida más arriba; antes bien, la

\footnotetext{
${ }^{4}$ Carta de Juan E. O’Leary a Luis A. de Herrera, Asunción, 24 de Julio de 1915, p.38.

${ }^{5}$ Carta de Juan E. O'Leary a Luis A. de Herrera, Asunción, 7 de agosto de 1915, p.39.

${ }^{6}$ Carta de Juan E. O'Leary a Luis A. de Herrera, Asunción, 7 de agosto de 1915, p.39.
} 
decisión de incluirla en el libro puede asociarse a su convicción de que había logrado que Rodó adoptase su interpretación sobre la guerra, una persuasión que el fallecimiento del uruguayo, en 1917, dos años antes de la publicación, habría contribuido, sin más, a cristalizar.

\title{
Las biografías de Francisco Solano López
}

La publicación de la primera edición de la biografía de Francisco Solano López que O'Leary diera a luz en 1920 tuvo, a juzgar por la correspondencia, más de una década de gestación. De acuerdo a su propio testimonio, a comienzos del año 1907 compró en Asunción, en la librería de Jordán y Villamil, "a 30 pesos", el texto sobre Juan Facundo Quiroga que compilaba las quince conferencias que el argentino David Peña había dictado en Facultad de Filosofía y Letras de la Universidad de Buenos Aires, y que tuvieron amplia resonancia por la defensa que en ellas hacía del caudillo riojano(Brezzo y Micheletti, 2016; Micheletti, 2015). Poco después, 0’Leary le remitió a Peña una carta en la que, luego de presentarse, le manifestaba la identificación con sus ideas, con el espíritu que, según entendía, había inspirado el estudio sobre el caudillo argentino:

\begin{abstract}
Años hace que me consagro a una obra semejante desde las columnas de la prensa de mi país. No le asombre, pues, mi actitud, que ella es hija del entusiasmo que no puede menos que producirme esta afinidad entre su pensamiento y el mío. Cuan pocos son los hombres que, como usted, se atreven a desafiar los prejuicios en nombre de la justicia histórica. Yo que he combatido por todas partes en mi país brego en defensa de las glorias de mi patria, aprecio en su justo valor su actitud. Yo sé las luchas, los trabajos, las amarguras que importa este noble apostolado. Créame, pues, su admirador y cuénteme en el número de los que le acompañan en su cruzada de vindicación iniciada con el monumento al más grande argentino -Alberdi- y meritoriamente continuada en su último libro. (BNP- CJO. Diario de Juan E. O’Leary. Cuaderno № 1. San Lorenzo, 3 de enero de 1907)
\end{abstract}

Se trasunta la admiración de 0'Leary hacia el autor argentino en cuyas ideas puede filiar su propia posición historiográfica; se hace nítido el claro sentido de exaltación patriótica que pretende conferir a su labor como historiador del Paraguay, y la operación que ha puesto en marcha para trasformar a Francisco Solano López en héroe máximo y mártir sacrificado de la nación paraguaya.

El inicio del contacto epistolar con Peña, que tendrá expresiones intermitentes en los años siguientes, parece funcionar como ante-texto de la obra que daría a conocer trece años después con el título El Mariscal López. Según le escribiera a Peña, su propósito principal consistía en reivindicar la actuación del presidente paraguayo durante la guerra y demostrar la injusticia de los atributos de bárbaro, déspota y sanguinario con los que las lecturas clásicas sobre el conflicto, asociadas a la 


\section{Cartas prodigiosas. Juan E. O'Leary y los entresijos de la edición de sus relatos históricos sobre la Guerra del Paraguay (1919-1929)}

tradición historiográfica liberal, caracterizaban a López hasta entonces. (Baratta, 2014; Reali, 2012).

En ese propósito de rehabilitación histórica, O'Leary publica la biografía de López, en 1920, con una extensión de 374 páginas y una tirada de 2000 ejemplares que, según el testimonio del autor, "se vendieron en dos semanas sin que hubiera tiempo de difundirla fuera de la capital". De modo que poco después inició la preparación de una segunda edición para la cual redactó un nuevo capítulo -la de 1920 abarcaba 26 capítulos, la segunda estaría compuesta por 27 capítulos - al que tituló "La glorificación del vencido", e invitó al escritor venezolano Rufino Blanco Fombona para que redactara el prólogo.

O’Leary y Blanco Fombona -este último residía desde hacía algunos años en Madridmantenían correspondencia desde mediados de la década de 1910; consta que o'Leary acompañaba sus cartas con publicaciones de su autoría y que conversaron, incluso, sobre la posibilidad de una segunda edición, aunque resumida, del libro Nuestra Epopeya, con el sello de la Editorial América que fundara y dirigiera Blanco Fombona en Madrid, si bien, finalmente, la edición madrileña no se concretó.

El escritor venezolano, a quien la invitación de O'Leary le llegó en circunstancias familiares dolorosas por el fallecimiento de su hijo pequeño, declinó la propuesta. La carta que le dirigió al historiador paraguayo para justificar su decisión reviste interés por los juicios que desenvuelve sobre el Mariscal López y sobre el lugar de O’Leary en la historiografía paraguaya:

El encargo que Ud. me da de prologar su libro sobre nuestro gran Solano López es de lo más lisonjero que he recibido en la vida, pero jay! es también de los más arduos. Para hablar de la actuación y del alma de Solano López hay que prepararse debidamente. Yo carezco de esa preparación y como no me conformaría con cuatro palabras para salir del paso me niego a aceptar el altísimo honor que usted me discierne, ya que por el momento me es imposible dedicarme a otras tareas que interrumpan las que tengo entre manos. Yo he hecho, dentro de mis medios, lo posible porque esta gran figura americana, oscurecida por el odio de dos pueblos fuertes y ricos resplandezca en nuestro horizonte. Aun haré más. No crea, pues, que mi negativa, que es la negativa a aceptar un honor que no me creo en capacidad de merecer obedezca sino a las expuestas razones. Ud., además, querido O'Leary, ha llegado a una altura en que no necesita que nadie le tienda la mano ¿No es verdad? (BNP-CJO. Correspondencia oficial y privada. Carpeta XXXVI. Madrid, 21 de julio de 1921)

Las razones de Blanco Fombona no inhibieron a O'Leary. Por el contrario, cuatro años después transcribirá el texto completo de esta misiva y la publicará, a manera de carta-prólogo, en la segunda edición de su biografía sobre López a la que titulará El Mariscal Solano López. O'Leary usó la carta de Blanco Fombona, a quien define como "el más alto escritor de América en nuestros días", al igual que hiciera con la 
de Rodó, para su propia legitimación como autor $\mathrm{y}$, en este caso, bien puede sostenerse, para la rehabilitación de su biografiado.

\section{El Centauro de Ibicuy}

Pero quizás las cartas más prodigiosas, increíbles o asombrosas, son aquellas vinculadas a la edición de la biografía del general Bernardino Caballero que O’Leary publicó en Paris en 1929.

Desde el año 1925 0'Leary se hallaba en Madrid, acreditado como Encargado de Negocios del Paraguay, aunque pasaba varios meses al año en Paris, ciudad en la que residía Ramón Caballero, hijo del general Bernardino Caballero, que encabezaba la legación de Paraguay en Francia. ${ }^{7}$ En la capital española 0'Leary cultivaba relaciones de amistad con el escritor mejicano Carlos Pereyra, con el venezolano Laureano Valenilla Lanz y con el ya mencionado Rufino Blanco Fombona, entre otros intelectuales latinoamericanos residentes en Europa y que aparecen aglutinados en torno a la Editorial América que, como ha sido mencionado, fundara Fombona en Madrid. ${ }^{8}$

La correspondencia de 0'Leary da cuenta que en el mes de abril de 1927 había finalizado la redacción de la obra titulada El Centauro de Ybicuy. Vida heroica del general Bernardino Caballero en la Guerra del Paraguay. La biografía del militar paraguayo, uno de los hombres más cercanos al Mariscal López, era relatada en el transcurso de veinte capítulos que abarcaban desde el momento en que se presentó en el campamento de Cerro León, en vísperas del inicio de las acciones militares, hasta su presencia en Cerro Corá y su posterior experiencia en la condición de prisionero, en Río de Janeiro.

Fue a instancias de Ramón Caballero que O'Leary hizo llegar al jefe del Estado Mayor italiano, Mariscal Pietro Badoglio -con quien Caballero socializara en el ambiente diplomático- una copia del manuscrito y una invitación a redactar el prólogo. El 1 de agosto de 1927, desde Roma, Badoglio escribió a Caballero una extensa carta en la que concluía que "luego de haberlo leído y releído con mucha atención [la biografía del general Bernardino Caballero] he llegado a la conclusión, para mí dolorosa, que no me es posible escribir el prefacio". ${ }^{9}$ Comenzaba por manifestar que consideraba indispensable que quien escribía un prefacio "debe aprobar en todo la sustancia y la forma del libro. Diré casi algo más: el presentador del libro se debe transformar en heraldo de las ideas de su contenido y deberá ser, por lo tanto, una especie de propagandista. Así lo entiendo al prefacionista". Y, aunque la personalidad de

\footnotetext{
${ }^{7}$ Ramón Caballero era hijo del general Bernardino Caballero y de María Concepción Díaz de Bedoya. Residió muchos años en Europa, ocupando diversos cargos diplomáticos en representación del Paraguay. Se casó con una parisina, Martha Cohen (1893-1988).

${ }^{8}$ La biblioteca de 0'Leary, recientemente catalogada, contiene los principales títulos de la Editorial América. Véase Catálogo bibliográfico de la Colección Juan E. O'Leary. Asunción, Secretaría Nacional de Cultura, 2019.

${ }^{9}$ BNP-CJO, Correspondencia pública y privada, Carpeta LXI.
} 


\section{Cartas prodigiosas. Juan E. O’Leary y los entresijos de la edición de sus relatos históricos sobre la Guerra del Paraguay (1919-1929)}

O'Leary, a quien no conocía personalmente, le resultaba "notablemente simpática y su alto patriotismo no podía sino apreciarse", no veía posible acceder a la solicitud. Una lectura atenta de la extensa carta nos permite razonar que la imposibilidad residía en el profundo disenso de Badoglio respecto del enfoque adoptado por O’Leary para relatar la biografía:

La figura de ese purísimo héroe se impone por sí mismo a la admiración de todos aquellos que aman una Patria. Después de cinco años de lucha, Caballero se alza sobre todos por su ardiente amor patrio, por la fidelidad a su jefe supremo, por el valor sobrehumano, por la genialidad de sus acciones guerreras. El pintor que lo debe presentar al público tiene una sola misión: reproducirlo como fue, simple y grande, sin ningún artificio, sin ninguna alteración. Alguna pincelada que busque algún efecto especial no es apropiada a este cuadro. Y así, escribiendo la historia del héroe, esta debe ser como sus acciones: profundamente serena, humana, simple, aquella debe ser una historia verdadera. ${ }^{10}$

Se desprende pues, que, para Badoglio, la obra consistía en una "biografía inventada", y que la razón de esa deformación había que buscarla en la función que el escritor paraguayo otorgaba a la escritura de la historia de la guerra:

...el ánimo ardiente y apasionado de O’Leary, excitado por la santa misión que se ha impuesto de exaltar las grandes gestas del heroico Paraguay no ha podido trazarse límites muy bien definidos en su exposición y si los ha trazado, el fuego lo ha casi siempre llevado fuera de aquellos. Su libro, por lo tanto, no es una historia, sino más bien una polémica continua. Y esa polémica, no siempre serena, también es injusta y a menudo alcanza un resultado, ciertamente no buscado por el autor, a saber, es contraproducente, como dicen los portugueses. ${ }^{11}$

Ese estilo combativo, más ensayístico que erudito, determinaba que la obra adoleciese de la correspondiente rigurosidad. Badoglio desciende a los contenidos de algunas secciones del relato en las cuales se hacía más flagrante esa debilidad. Así, respecto al Capítulo IX del libro que narraba el asalto a Tuyutí, producido en el mes de noviembre de 1867, 0’Leary escribía lo siguiente:

Tuyutí era entonces una pequeña ciudad alegre y confiada en la que nada faltaba de los refinamientos y comodidades de la vida social. En 18 meses de ocupación, aquel ingrato arenal había visto surgir casas, teatros, iglesias...Su población femenina era considerable. Las más hermosas meretrices del Plata iban allí, en pos del Pacto imperial, convirtiendo en muelle Cápua aquel inmenso cementerio, empapado de sangre. En sus contornos se hizo

\footnotetext{
10 BNP-CJO, Correspondencia pública y privada, Carpeta LXI.

11 BNP-CJO, Correspondencia pública y privada, Carpeta LXI.
} 
agricultura...Sus pobladores hacían vida regalada, dejando que corriera el tiempo, convencidos de que este era su mejor aliado. Pero aquella holgura sibarita tenía que quebrantar la moral del enemigo y minar la disciplina. Caxias intentó una reacción, explicable en sus años, contra los excesos de la prostitución y las repugnantes manifestaciones de todos los vicios. Nada consiguió y hubo de apresurar la salida de su ejército de aquel antro pestilente. ${ }^{12}$

En relación a este tramo, Badoglio le objetaba a O'Leary que “declarar, en un inciso, que el Duque de Caxias se mostró severo para tratar de abolir o al menos disminuir el número de las prostitutas en Tuyutí sólo porque siendo él viejo no podía más aprovechar de similares distracciones es una afirmación no serena". En igual sentido, en el Capítulo XIII, dedicado al relato de Ytororó, O’Leary describía la acción del general brasileño Manuel Osorio quien, según su versión, viendo la férrea defensa de los paraguayos, decidió tomar un camino que podía llevarle, sin ser sentido, a la retaguardia de sus enemigos, pero el guía se perdió y "Osorio no pudo llegar a tiempo para intervenir con eficacia en la batalla”. El militar italiano despliega sus reparos a esta interpretación del modo siguiente:

El tachar de deslealtad a Osorio porque en Ytororó buscaba de aggirare la posición para caer sobre la retaguardia de Caballero, es injusto. El calificar a todos los generales brasileños, argentinos y orientales como ineptos y temerosos y a toda la tropa enemiga como casi siempre cobarde, es contraproducente. Evidentemente vale más vencer a un enemigo hábil y valeroso que vencer a un adversario torpe y con marcada tendencia a la fuga. ${ }^{13}$

Estas impugnaciones de Badoglio no eran incompatibles, empero, con la admiración por el espíritu que había guiado a 0’Leary en la redacción del relato:

¿Cómo querer, él me responderá, que un paraguayo puede ser sereno al narrar todo el martirio de su pueblo? ¿Cómo pretender objetividad y calma de exposición cuando la más despiadada crítica cayó contra López y contra sus soldados, calificándolo al primero, de bárbaro tirano y a los segundos como una masa de esclavos más aterrorizados por aquel jefe que por el enemigo? ¿Cómo podremos escribir nosotros la historia verdadera y serena cuando aquella no es escrita por los vencedores? Comprendo, mi buen O’Leary, vero bardo de tu pequeño gran país, comprendo muy bien tu estado de ánimo. Comprendo que tú quieras gritar a todo el mundo que el pueblo paraguayo es valeroso y que si ha salido vencido ha sido por el número no por defecto de sus defensores ¡Comprendo que tú quieras de una buena vez demoler todas las leyendas de barbarie, de actos desleales, de procedimientos inicuos, que hacen recaer todos juntos la miseria del

12 BNP-CJO, Correspondencia pública y privada, Carpeta LXI.

${ }^{13}$ BNP-CJO, Correspondencia pública y privada, Carpeta LXI. 


\title{
Cartas prodigiosas. Juan E. O'Leary y los entresijos de la edición de sus relatos históricos sobre la Guerra del Paraguay (1919-1929)
}

vencido! ¡Vae Victis! Sí, todo esto lo comprendo y como soldado que he dado cuanto he podido por la Patria mía, te aplaudo de corazón y le auguro al Paraguay una completa resurrección material y moral.14

El Mariscal italiano advertía en la nota a Ramón Caballero que acompañaba la respuesta a la invitación de O'Leary: “Quiera, vuestra Excelencia, perdonar mi decisión y hacerme perdonar por O’Leary. Escriba él, que sabe y puede, la historia humana de Bernardino Caballero y yo estaré con él". De modo que Badoglio no ponía en duda las condiciones militares y el heroísmo de Caballero, hechos que no le merecían reservas, sino la forma en que el autor había construido al biografiado, esto es, como un militar que a lo largo de toda la obra aparecía, invariablemente, como "bueno, hermoso y casto".

Exactamente un mes después, el 2 de setiembre de 1927, O'Leary respondía a la carta para explicar el "tono" adoptado en su relato. Si bien algo extensa, nos parece necesario ofrecer la cita completa:

\begin{abstract}
Respecto al tono de mi libro, le diré que es el que corresponde a una obra de combate, llamada a vindicar a un héroe calumniado. Está Ud. en un error al creer que el Mariscal López es el único calumniado de nuestra historia. El general Caballero ha sido igualmente maltratado. Se le ha negado todo mérito, se le ha presentado como un hombre torpe y cobarde, se le ha llamado el general de las "eternas derrotas", el "general avestruz", se le ha desconocido sistemáticamente el valor militar de su acción guerrera. Y yo hago obra de combatiente, entro a luchar con sus denigradores -que son los denigradores de mi patria y de sus héroes- con todo el fuego del hijo que defiende a su madre. A mi modo doy las últimas batallas de la guerra del 65 , que no terminó en Cerro Corá, que sigue todavía, ya que después de aniquilar materialmente al Paraguay han pretendido aniquilarlo moralmente, negándole hasta la gloria de su vencimiento heroico. Y no creo que mi libro sea contraproducente, por el contrario creo que su sinceridad y hasta la pasión con que está escrito -santa y respetable pasión- ha de conmover a todas las almas generosas y hasta conquistar las simpatías de todos los que aman a su tierra y son capaces de comprender nuestro dolor. ${ }^{15}$
\end{abstract}

Agregaba que:

Yo, mi querido Mariscal, no niego valor a los caudillos enemigos. Eso sí, no disimulo la indudable cobardía de los que lo fueron en realidad. Admiro y reconozco el heroísmo de un Osorio y de un Portoalegre, pero castigo a los pusilánimes que después de temblar ante nuestra bandera nos han presentado como esclavos que íbamos a las batallas bajo el látigo de un tirano, peleando por temor a un amo cruel e iracundo, no por amor a nuestra

\footnotetext{
${ }^{14}$ BNP-CJO, Correspondencia pública y privada, Carpeta LXI.

15 BNP- CJO, Correspondencia oficial y privada. Carpeta LXII. Paris, 2 de setiembre de 1927.
} 
patria. Si usted conociera toda la literatura de esa guerra, justificaría, tenga por seguro, mi actitud. ${ }^{16}$

Y, por otra parte, 0’Leary no creía en un relato riguroso:

Por lo demás, la historia objetiva no es posible, es pura hipocresía, la historia es y debe ser espejo animado de la vida, no cementerio de estatuas. Es resurrección, como dijo Michelet. En ella deben chocar de nuevo las pasiones que forman la trama de nuestra existencia. El historiador es, ante todo, un hombre, que se transporta al pasado, que agita el mar muerto de lo que fue, que interviene en el drama fenecido, participando de las inquietudes de sus actores. No es un Dios que contempla su obra desde lo alto y la reproduce por imperio de su voluntad omnipotente. No. En él revive el pasado y él mismo es una simple prolongación del pasado. El historiador de una guerra es así, siempre, un combatiente, un actor más de la lucha, un último sobreviviente que habla por todos los que murieron. Desde Jenofonte hasta Thiers no se ha dado ni se dará el historiador "imparcial", el historiador "sereno", el que hago lo que se ha dado en llamar "historia objetiva". El señor Mariscal lo sabe demasiado. ${ }^{17}$

Cabe recordar aquí que O’Leary había conocido al general Bernardino Caballero desde 1904 y cultivado una cercana amistad hasta el año 1912, cuando este último falleció. De modo que, muy probablemente, disponía, al momento de acometer la redacción de su biografía, de un testimonio en primera persona, de un manojo de recuerdos que, seguramente, habrían discurrido en ocasión del trato personal. Incluso la cercanía con Caballero, fundador de la Alianza Nacional Republicana, había sido decisiva para que O'Leary se afiliara a esa agrupación política. Sin embargo, en la biografía no es posible hallar ningún rastro "documental" que remita al testimonio del biografiado.

Hacia el final de la respuesta a Badoglio, O'Leary vuelve a retomar uno de los argumentos que sostuviera en 1902, cuando publicara los Recuerdos de Gloria y durante la polémica con Cecilio Báez, para enfatizar su visión del pasado del Paraguay, esto es, su condición de excepcionalidad:

El caso de nosotros, los paraguayos, es excepcional. Nadie ha sufrido como nosotros. Nuestro infortunio no tiene igual en el mundo ni en el tiempo. Porque no se ha visto nunca el degüello de todo un pueblo, durante cinco años, ni una crueldad igual para difamarlo. Hemos sufrido y sufrimos un tormento que escapó al Dante. Somos los condenados de un "dolor sin esperanza”. Sangra nuestro corazón... Por lo demás, señor Mariscal, está en su derecho el querer permanecer neutral en esta contienda. Tal vez hice mal en pretender unir mi oscuro nombre al suyo resplandeciente. Me arrepiento y le pido me perdone. En realidad, yo no pretendí romper su neutralidad,

16 BNP- CJO, Correspondencia oficial y privada. Carpeta LXII. Paris, 2 de setiembre de 1927.

17 BNP- CJO, Correspondencia oficial y privada. Carpeta LXII. Paris, 2 de setiembre de 1927. 


\section{Cartas prodigiosas. Juan E. O'Leary y los entresijos de la edición de sus relatos históricos sobre la Guerra del Paraguay (1919-1929)}

sólo aspiré a que el héroe moderno de Italia, tuviera una palabra de simpatía para el héroe de mi libro, compañero de un héroe italiano. Yo creí que le hubiera sido posible hablar como técnico de la actuación militar de Caballero, sin inmiscuirse en lo que podemos llamarla parte política de la guerra. ${ }^{18}$

Badoglio se mantuvo firme en su decisión. ${ }^{19}$ Esto condujo a 0'Leary a invitar a Carlos Pereyra para que se encargase del prólogo. A mediados del mes de marzo de 1928 el escritor mejicano le aseguraba que: "Hice un prólogo que no me gustó. Estoy haciendo otro que acaso no me disguste. Ya sabe usted que el asunto y el autor, sobre todo, me interesan extraordinariamente. Dios me conceda salir como lo desea, pues nada deseo más que un desempeño digno de quien me lo encomendó, haciéndome una distinción inmerecida".20

$Y$, en una misiva siguiente, le confirmaba: "por fin ya tengo eso listo... Mañana o pasado mañana se lo enviaré. Perdóneme. Necesito de toda su indulgencia por un retardo que es absolutamente involuntario, pues me llovieron las exigencias más apremiantes". ${ }^{21}$

Juan O’Leary le respondía poco después para manifestar su satisfacción:

He recibido su generoso prólogo. No sé cómo expresarle mi gratitud y la de mi Patria. No esperaba menos de su amistad y de su grande y justiciero corazón. Sus palabras valdrán más, mucho más que todo mi libro...Gracias, mil, un millón, infinitas gracias. Estoy muy contento y muy orgulloso. Ud. ha colmado mis deseos. Y me figuro la impresión que van a causar sus palabras en mi país. Ahora sí que se le va a querer en el Paraguay, con ser ya mucho lo que se le quiere y admira. Tomo buena nota de lo que me dice en su carta. ${ }^{22}$

De modo que, en los primeros meses de 1929, con el sello Le Livre Libre, de Paris, vio la luz de la imprenta la biografía en español de El Centauro de Ybycui. La correspondencia da cuenta que, en los años siguientes, O'Leary y Ramón Caballero iniciaron diligencias para imprimir también una edición en francés. Encomendaron a Jean Tild, un traductor de Rennes, la preparación del manuscrito y, si bien existe documentación que prueba que las gestiones se extendieron hasta muchos años después, no se ha hallado, de momento, confirmación de la edición en lengua francesa. ${ }^{23}$

\footnotetext{
${ }^{18}$ BNP- CJO, Correspondencia oficial y privada. Carpeta LXII. Paris, 2 de setiembre de 1927.

${ }_{19}$ Diez años después Pietro Badoglio accedió a redactar el prólogo a la obra del general italiano Rodolfo Corselli, La guerra americana de la Triplice Alleanza contro el Paraguay, Módena, 1938, 614 páginas.

${ }^{20}$ BNP- CJO. Correspondencia oficial y privada. Carpeta LXIII. Villa de las Acacias, Madrid, 15 de marzo de 1928.

${ }^{21}$ Ibídem. Villa de las Acacias, Madrid, 10 de abril de 1928.

22 BNP- CJO. Correspondencia oficial y privada. Carpeta LXII. París, 17 de abril de 1928.

${ }^{23}$ Ibídem. Carpetas LXXXVII y LXXXVIII. Ha sido posible localizar, en el archivo epistolar de Juan O’Leary, un presupuesto mecanografiado para la impresión de "La vida Heroica del General
} 


\section{Conclusiones}

La correspondencia examinada devela la estrategia de Juan E. O'Leary de solicitar a reconocidos letrados u hombres públicos que prologasen sus obras sobre la Guerra del Paraguay como una búsqueda de aliados dentro de la región platense y en Europa para consolidar una lectura revisionista de ese conflicto, así como para legitimar su propio quehacer intelectual. En esos propósitos puede situarse el temprano contacto epistolar que el autor paraguayo buscó con el argentino David Peña, figura clave de la revisión de la lectura clásica de diversos procesos del pasado argentino, incluida la Guerra del Paraguay, y en la que aparece la mayoría de los tópicos que desarrollará in extenso el revisionismo posterior.En el mismo objetivo se inscriben los intercambios intelectuales y las solicitudes para prologar sus relatos sobre la guerra al escritor venezolano Rufino Blanco Fombona y al mejicano Carlos Pereyra.

Más sinuoso aparece el uso que hace 0'Leary de la carta que le remitiera José Enrique Rodó y en la que se extiende sobre su interpretación sobre la Guerra del Paraguay, publicada después del fallecimiento del uruguayo, y a la que presentaría como una prueba de adhesión a su visión de la guerra.

El estudio cruzado de la correspondencia y de la producción histórica de 0'Leary resumido en este trabajo parece otorgar mayor nitidez al proceso de gestación de sus relatos sobre la Guerra del Paraguay. El uso de la carta como ante-texto, producido en la esfera privada para luego reelaborar los contenidos dirigidos a la esfera pública encuentra en la carta enviada a David Peña trece años antes de la publicación de la biografía de Solano López el ejemplo más representativo.

Las cartas analizadas develan, asimismo, la operación política de O’Leary en el sentido de desentenderse de la objetividad histórica y de la compulsa documental en su lectura sobre la Guerra del Paraguay. En este sentido, las que rodean a la edición de la biografía del General Bernardino Caballero son las más características.

\section{Bibliografía}

Aurell, J. (2008). Del logocentrismo a la textualidad: la autobiografía académica como intervención historiográfica. Edad Media. Revista de Historia, № 9. Valladolid, pp. 192-222.

Caballero", fechado en noviembre de 1948, por 500 ejemplares (260.000 francos) y por 1000 ejemplares (320.000 francos), que confirma este propósito. Asimismo, el 2 de diciembre de 1949 Ramón Caballero le escribía a Juan O'Leary una carta anunciándole que estaba en proceso la impresión "su libro sobre mi padre" y que "con mil dólares estaremos satisfechos. El gobierno -huelga invocar las razones- debiera publicarlo. Sería una plata bien empleada. Puede que, en cambio, tendría que mandar menos diplomáticos trashumantes, que vienen -no hay otro objeto valedero- a hacerse piné porá". 


\section{Cartas prodigiosas. Juan E. O'Leary y los entresijos de la edición de sus relatos históricos sobre la Guerra del Paraguay (1919-1929)}

Aurell, J. (2014). Textos autobiográficos como fontes historiográficas: relendo a Fernand Braudel e Anne Kriegel. História, vol. 33, São Pablo, pp. 340-364.

Baratta. V. (2014). La Guerra del Paraguay y la historiografía argentina. Historia da historiografía, no 14, Ouro Preto, pp.98 - 115.

Baratti, D. y Candolfi, P. (2019). Vida y obra del sabio Bertoni. Asunción, Servilibro, 2019.

Biblioteca Nacional del Paraguay, Catálogo bibliográfico de la Colección Juan E. O’Leary. Asunción, Secretaría Nacional de Cultura, 2018.

Brezzo, L. (2012). Vivimos en tiempos de las más grandes reivindicaciones. Las cartas privadas entre dos letrados paraguayos durante la primera década del siglo XX: Gregorio Benites y Juan E. O Leary. Revista Paraguaya de Sociología, № 141, Asunción, pp.193-233.

Brezzo, L. y Micheletti, M. (2016). Libros, cartas, lecturas: la revisión de la historia en Argentina y Paraguay a través de los intercambios epistolares entre David Peña y Juan E. O'Leary. História da Historiografia, nº 20. Ouro Preto, pp. 14-30.

Brezzo, L. y Reali, M. (2017). Combatir con la pluma en la mano. Dos intelectuales en la Guerra del Chaco: Juan E. O'Leary y Luis Alberto de Herrera. Asunción: Servilibro.

Caballero Campos, H. (2017). Entre Clío y Astrea. La Biblioteca Paraguaya del Centro de Estudiantes de Derecho. Diálogos, no 21. Maringá, pp. 13-25.

Capdevila, L. (2008). Para una historia del tiempo presente paraguayo. Del pasado/presente entre dictadura y democracia: los historiadores bajo la dictadura. Res Gesta, no 46. Rosario, p. 37-59.

Halperin Donghi, T. (2008). Son memorias. Buenos Aires: Siglo XXI.

Micheletti, M. (2015). "Facundo Quiroga rehabilitado". Una aproximación al contexto de producción, repercusiones y aportes historiográficos del libro de David Peña (1906). Boletín del Instituto de Historia Argentina y Americana "Dr. Emilio Ravignani", no 42. Buenos Aires, pp. 125-153.

Myers, J. (2014). El epistolario como conversación humanista: la correspondencia intelectual de Alfonso Reyes y Genaro Estrada (1916-1939). Políticas de la Memoria, Buenos Aires, no 15. Buenos Aires, pp. 53-70.

Myers, J. (2010). El intelectual diplomático: Alfonso Reyes, sustantivo. En Altamirano, C. (Org.). Historia de los Intelectuales en América Latina: Los avatares de la "ciudad letrada" en el siglo XX. Buenos Aires: Katz, Tomo 2, pp. 82-97. 


\section{Liliana M. Brezzo}

O’Leary, J. (1919). Nuestra Epopeya. Guerra del Paraguay. Asunción: La Mundial.

O’Leary, J. (1920). El Mariscal López. Asunción: La Prensa.

O’Leary, J. (1925). El Mariscal Solano López. Madrid: Félix Moliner.

O’Leary, J. (1929). El Centauro de Ibicuy. Vida heroica del General Bernardino Caballero. Paris: Le Livre Libre.

O’Leary, J. (2007). Recuerdos de Gloria. Compilación de Sebastián Scavone Yegros. Asunción: Servilibro.

Peiró, I. (2001). La contemplación de Narciso: la 'vocación autobiográfica' de los historiadores. En Ruiz Carnicer, M. y Frías Corredor, C. Nuevas tendencias historiográficas e historia local en España. Huesca: Instituto de Estudios Altoaragoneses, pp. 361-388.

Peluffo, A. y Maíz, C. (2018). Afectos, redes y epistolarios. Revista Landa, vol. 6, № 2. Santa Catarina, pp. 132-139.

Popkin, J. (2005). History, Historians, and Autobiography. Chicago: University of Chicago Press.

Reali, M. (2012). Los intercambios epistolares entre Luis A. de Herrera y Juan E. O'Leary en el período de surgimiento y consolidación de un movimiento historiográfico revisionista sobre la Guerra del Paraguay. En Casal, J. y Whigham T. (eds.). Paraguay en la historia, la literatura y la memoria. Asunción: Tiempo de Historia, pp. 391- 411.

Rivarola, M. (2007). En torno a la obra Ritter, de Xavier Careaga, en Diario ABC Color, Asunción.

Saitta, S. (2018). Son memorias, el autobiográfico juego de un tímido. Boletín del Instituto de Historia Argentina y Americana "Dr. Emilio Ravignani”, Número Especial homenaje a Tulio Halperin Donghi. Buenos Aires, pp. 155-167.

Recibido: $13 / 01 / 2019$

Evaluado:25/02/2019

Versión Final: 15/04/2019 